\title{
The Role of Circulating Tight Junction Proteins in Evaluating Blood Brain Barrier Disruption following Intracranial Hemorrhage
}

\author{
Xiaoyang Jiao,, ${ }^{1}$ Ping He, ${ }^{2}$ Yazhen Li, ${ }^{1}$ Zhicheng Fan, ${ }^{1}$ Mengya Si, ${ }^{1}$ Qingdong Xie, \\ Xiaolan Chang, ${ }^{1}$ and Dongyang Huang ${ }^{1}$ \\ ${ }^{1}$ Department of Cell Biology and Genetics, Shantou University Medical College, Guangdong 515041, China \\ ${ }^{2}$ Shantou University Medical College, Guangdong 515041, China \\ Correspondence should be addressed to Dongyang Huang; huangdy@stu.edu.cn
}

Received 16 July 2015; Revised 14 September 2015; Accepted 16 September 2015

Academic Editor: Lance A. Liotta

Copyright (c) 2015 Xiaoyang Jiao et al. This is an open access article distributed under the Creative Commons Attribution License, which permits unrestricted use, distribution, and reproduction in any medium, provided the original work is properly cited.

Brain injury after intracranial hemorrhage (ICH) results in significant morbidity and mortality. Blood brain barrier (BBB) disruption is a hallmark of ICH-induced brain injury; however, data mirroring BBB disruption in human ICH are scarce. The aim of this study was to assess the significance of circulating biomarkers in evaluating BBB disruption after ICH. Twenty-two patients with ICH were recruited in this study. Concentrations of the tight junction proteins (TJs) Claudin-5 (CLDN5), Occludin (OCLN), and zonula occludens 1 (ZO-1) and vascular endothelial growth factor (VEGF) and matrix metalloproteinase-9 (MMP9) were measured by using enzyme-linked immunosorbent assay in serum and cerebrospinal fluid (CSF) samples obtained from patients with ICH. The white blood cell (WBC) count in blood and CSF, albumin (ALB) levels in the CSF (ALB ${ }_{\text {CSF }}$ ), and the BBB ratio were significantly higher in the ICH than in controls $(p<0.05)$. Significantly higher levels of CLDN5, OCLN, ZO-1, MMP-9, and VEGF in CSF were observed in the ICH group; these biomarkers were also positively associated with BBB ratio $(p<0.05)$. Our data revealed that circulating TJs could be considered the potential biomarkers reflecting the integrity of the BBB in ICH.

\section{Introduction}

Spontaneous intracranial hemorrhage (ICH) results in significant morbidity and mortality, thirty-day case fatality rates which range from $40 \%$ to $50 \%$ in most studies [1-3]. Hypertension is the most important risk factor for ICH [4], where clinical treatment options remain limited, in part, due to the poorly defined sequelae underlying injury progression. Brain injury occurs in the acute injury phase following ICH $[5,6]$. BBB disruption is a hallmark of $\mathrm{ICH}$-induced brain injury, which contributes to edema formation, the influx of leukocytes, and the entry of potentially neuroactive agents into the perihematomal brain [7-9]. The degree of BBB breakdown has been directly correlated with late functional outcome [10].

The BBB inhibits transcellular or paracellular passage of molecules across it by an elaborate network of complex tight junctions between the endothelial cells [11]. Tight junction proteins (TJs) are the main components of the BBB [12]. Claudin-5 (CLDN5), ZO-1, and Occludin (OCLN) are the main components of TJs in brain endothelial cells to maintain the BBB integrity. CLDN5 knockout mice presented increased BBB permeability [13]; on the contrary, inhibiting decreased expression of CLDN5 has been shown to reduce brain edema and hemorrhagic transformation [14]. The expressions of ZO1 and OCLN were significantly decreased after subarachnoid hemorrhage (SAH) [15], and degrading ZO-1 and OCLN in endothelial tight junction can facilitate capillary leakage, which is responsible for the increase in BBB permeability after $\mathrm{SAH}$ [16]. Increased BBB permeability after ICH has been noted in parallel with edema formation and BBB disruption leading to vasogenic edema [17]. Presence of TJs in the neurovascular unit is one likely component of the brain's armamentarium against hemorrhage; however, the role of TJs in mirroring the $\mathrm{BBB}$ disruption in human $\mathrm{ICH}$ is scarce. 
The proteins released from damaged cells into the bloodstream would reveal the BBB disruption, which might be potential biomarkers. Protein S100B appears in plasma after ICH and its levels correlated with ICH outcome [18]. Albumin is currently the conventional biomarker used in clinical practice to assess the integrity of $\mathrm{BBB}$. The quotient of $\mathrm{CSF} /$ serum albumin (also called $\mathrm{BBB}$ ratio) is determined by the concentration of albumin in blood and CSF, which have been used extensively to mirror the $\mathrm{BBB}$ disruption in neuroinflammatory disease or in tumor CNS metastasis [19]. However, serum concentrations of S100B and albumin are influenced significantly by status of peripheral circulation and blood released from the hematoma after $\mathrm{ICH}$, leading to the potential inaccuracies in judging the disease severity.

Biomarkers reflecting the severity of ICH could increase the discriminative power for outcome evaluation. Two areas of extensive research are neuroimaging and circulating biomarkers. Circulating TJs are currently becoming the hallmark of BBB integrity [20]. A recent study revealed that the release of TJs into the circulation is expected to occur during brain ischemia; higher serum concentrations of TJs OCLN and CLDN5/ZO-1 ratio were observed in ischemic stroke patients. Analyzing serum TJs is an effective way to screen clinical deterioration caused by hemorrhagic transformation in ischemic stroke patients [21]. Although the mechanism underlying the $\mathrm{BBB}$ disruption in $\mathrm{ICH}$ remains unclear, inflammatory mediators (such as matrix metalloproteinases (MMPs) and vascular endothelial growth factor (VEGF)) are the crucial factors degrading the TJs. Elevated MMPs and VEGF increased BBB permeability and worsened brain edema after ICH [22-24]. Thus, TJs, degraded by MMPs and VEGF, may be released into CSF after ICH.

Computed tomography (CT) and magnetic resonance imaging (MRI) are the key part of the initial diagnosis, which demonstrate the hematoma size and location of the hemorrhage. Standard CT can detect up to $95 \%$ of ICH; however patients presented several days after a small ICH may have little blood visible on a CT scan. MRI is known to overestimate the size of microbleed (the "blooming effect"), with MRI diameter on average more than $150 \%$ of pathological lesions $[25,26]$. It is common for patients' condition to not allow MRI imaging to be done on a predetermined schedule, or earlier in the course of ICH. In addition, image techniques reflect the morphology rather than the function of the $\mathrm{BBB}$. Under this circumstance, the availability of circulating biomarkers may assist in selection of those patients who require further investigation [27]. ICH results in the release of numerous blood/blood vessel broken products into the CSF, circulating through the ventricles, subarachnoid space, and parenchyma, and these substances have a long resistance time in CSF and CNS, making CSF be a choice for novel biomarker discovery [28-30]. Measurement of biomarkers in CSF may reflect accurately the status of $\mathrm{ICH}$ and serve as surrogate endpoints for experimental or nonoptimized therapies; some of these may be used in the early identification and diagnosis of the condition and its sequelae, as well as for determining the prognosis [31]. In this study, we assessed the changes of CLDN5, OCLN, and ZO-1 in both CSF and serum in patients with ICH to reveal whether circulating TJs provide a valuable predictor for the BBB disruption following $\mathrm{ICH}$.

\section{Method}

2.1. Patients. This prospective study was approved by the Shantou University Medical College; written informed consents were obtained from the patients or their surrogates. Twenty-two patients were recruited during 2013-2014. Patients suspicious of ICH underwent immediately CT scanning or MRI after hospital admission. The diagnosis of $\mathrm{ICH}$ was confirmed by CT or MRI. The Digital Imaging and Communications in Medicine (DICOM) format was analyzed centrally for the measurement of hematoma size. As the CSF is very hard to get in health individuals, seventeen patients with disease other than $\mathrm{ICH}$ were enrolled as the control for comparison of the biomarkers in CSF. The details of control were shown in Table 1 .

2.2. Hematoma Size Measurement. The size of the ipsilateral hemisphere and the infarcted area were measured using a standard computer-assisted analysis technique (ImageJ). Calculation of hematoma size was performed using the formula: size of infarcted area/ipsilateral hemisphere $\times 100$ and shown as percentage of the whole hemisphere. The sizes were shown as mean $\pm \mathrm{SD}$.

2.3. Sample Collection and Measurement. Paired serum and CSF samples were obtained on patients admission. Lumbar puncture was used for diagnostic or treatment purposes. CSF sample was collected before treatment. Samples were immediately centrifuged, and supernatants were stored at $-80^{\circ} \mathrm{C}$ until assessment. CSF cytology, total protein, and electrolyte were measured in all of the patients before therapy. The serum biomarkers were measured according to the same protocol as described for the CSF. VEGF and MMP-9 in CSF were measured by ELISA (R\&D America Company). CSF and serum TJs levels were measured by ELISAs (ELISA kits from Cusabio (America) company).

2.4. Evaluation of $B B B$ Integrity. The assessment of the $B B B$ integrity in the patients and the controls was performed as previously described [19]. We explored whether the ratio of CLDN5, OCLN, and ZO-1 in CSF and serum reflects BBB disruption. We used the following formula:

$$
\text { CLDN5 index }=\frac{\text { CLDN5 }_{\mathrm{CSF}} / \mathrm{CLDN}_{\text {Serum }}}{\text { Albumin }_{\mathrm{CSF}} / \text { Albumin }_{\text {Serum }}} .
$$

Index of OCLN and ZO-1 was calculated with the same equation.

2.5. Statistical Analyses. Statistical analyses were performed using SPSS for Windows version 10.0. All continuous variables were reported as medians with interquartile ranges (IQR). Mann-Whitney $U$ test, Spearman rank correlation, a multivariate regression analysis, and binary logistic regression were applied in the study. A cluster analysis (CA) and a principal component analysis (PCA) were performed to obtain significant principal components. $p<0.05$ was considered statistically significant. 
TABLE 1: General character of the controls.

\begin{tabular}{lcccccccccc}
\hline Controls & Gender & Age $(\mathrm{yrs})$ & $\mathrm{RBC}_{\mathrm{CSF}}$ & $\mathrm{WBC}_{\mathrm{CSF}}$ & $\mathrm{Glu}_{\mathrm{CSF}}$ & $\mathrm{Cl}_{\mathrm{CSF}}$ & $\mathrm{Alb}_{\mathrm{CSF}}$ & $\mathrm{BBB}_{\text {ratio }}$ & Diagnosis \\
\hline 1 & $\mathrm{M}$ & 12.00 & 1 & 11.00 & 3.66 & 128.10 & 0.40 & 9.69 & CNS IRS \\
2 & $\mathrm{~F}$ & 28.00 & 1 & 2.00 & 3.51 & 133.00 & 0.07 & 2.08 & Headache \\
3 & $\mathrm{M}$ & 5.00 & 3 & 25.00 & 3.52 & 123.50 & 0.28 & 7.22 & CNS IRS \\
4 & $\mathrm{M}$ & 28.00 & 0 & 1.00 & 3.26 & 128.60 & 0.49 & 13.17 & Headache \\
5 & $\mathrm{M}$ & 2.50 & 0 & 4.00 & 3.45 & 122.70 & 0.12 & 3.13 & Headache \\
6 & $\mathrm{M}$ & 50.00 & 0 & 38.00 & 3.46 & 108.00 & 1.01 & 23.82 & Viral encephalitis \\
7 & $\mathrm{M}$ & 15.00 & 2 & 2.00 & 4.75 & 119.00 & 0.21 & 5.48 & Headache \\
8 & $\mathrm{~F}$ & 12.00 & 1 & 5.00 & 3.35 & 131.00 & 0.21 & 4.94 & Suspected inflammation \\
9 & $\mathrm{M}$ & 43.00 & 0 & 49.00 & 3.73 & 124.90 & 0.47 & 13.28 & Viral encephalitis \\
10 & $\mathrm{M}$ & 29.00 & 0 & 20.00 & 3.11 & 127.20 & 0.49 & 12.63 & Viral encephalitis \\
11 & $\mathrm{M}$ & 15.00 & 20 & 65.00 & 4.32 & 128.70 & 0.37 & 8.71 & Viral encephalitis \\
12 & $\mathrm{M}$ & 57.00 & 3 & 5.00 & 3.99 & 122.00 & 0.71 & 18.83 & Suspected inflammation \\
13 & $\mathrm{M}$ & 5.00 & 1 & 5.00 & 3.20 & 124.80 & 0.33 & 8.51 & Suspected inflammation \\
14 & $\mathrm{M}$ & 16.00 & 1 & 45.00 & 3.12 & 124.50 & 0.49 & 13.14 & Viral encephalitis \\
15 & $\mathrm{~F}$ & 50.00 & 4 & 5.00 & 5.00 & 129.00 & 0.48 & 11.19 & Headache \\
16 & $\mathrm{M}$ & 35.00 & 2 & 48.00 & 3.89 & 134.80 & 0.80 & 20.41 & Viral encephalitis \\
17 & $\mathrm{M}$ & 3.00 & 20 & 19.00 & 4.67 & 131.60 & 0.31 & 7.06 & CNS IRS \\
\hline
\end{tabular}

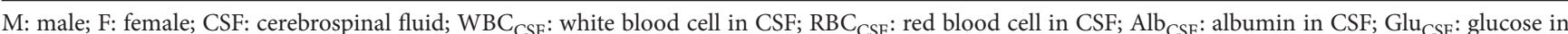
$\mathrm{CSF} ; \mathrm{Cl}_{\mathrm{CSF}}$ : chlorine in CSF; BBB ratio: $\mathrm{Alb}_{\mathrm{CSF}} \times 1000 / \mathrm{Alb}_{\text {Serum }}$; CNS IRS: CNS infection recovery stage.

\section{Results}

3.1. General Characteristic of Patients with $\mathrm{ICH}$ and the Controls. Patient demographic and clinical data were summarized in Table 2. Of the 22 patients, the mean age of $\mathrm{ICH}$ group was 55.05 (range 49.18-60.91); 12 were men and 10 were women. Hypertension is the most common cause of $\mathrm{ICH}$ in our patients, accounting for all cases. The mean systolic blood pressure (SBP) was 175.5 (range: $157.0-190.5 \mathrm{mmHg}$ ), and diastolic blood pressure (DBP) was 104.5 (range: 94.5$111.25 \mathrm{mmHg}$ ) in ICH patients. SBP was significantly associated with the patient's primary outcome.

The WBC in CSF $\left(\mathrm{WBC}_{\mathrm{CSF}}\right.$ ) and blood were significantly higher in the ICH than in the controls $(p<0.05)$, indicating inflammatory status existed in $\mathrm{ICH}$ patients. We did not find significant differences in parameters (RBC, HB, and $\mathrm{LDH}$ in blood, serum enzyme, and glucose and $\mathrm{Cl}$ in CSF) between the ICH patients and the controls $(p>0.05)$. The ALB in CSF $\left(\mathrm{ALB}_{\mathrm{CSF}}\right)$ and $\mathrm{BBB}$ ratio in $\mathrm{ICH}$ group were significantly higher than in controls $(p<0.05)$; on the contrary, $\mathrm{ALB}_{\text {Serum }}$ in ICH was significantly lower than in controls $(p>0.05)$.

3.2. Serum and CSF CLDN5, OCLN, and ZO-1 Levels in Patients with ICH and the Controls. There were significantly higher levels of CLDN5, OCLN, and ZO-1 in CSF $\left(\mathrm{CLDN} 5_{\mathrm{CSF}}, \mathrm{OCLN} \mathrm{CSF}\right.$, and $\mathrm{ZO}-1_{\mathrm{CSF}}$ ) observed in $\mathrm{ICH}$ than in controls; specifically, CLDN $5_{\mathrm{CSF}}$ was 8.28 -fold higher than that in control, OCLN $\mathrm{CSF}_{\mathrm{CF}}$ wa.78-fold higher than in control, and $\mathrm{ZO}-1_{\mathrm{CSF}}$ was 5.16 -fold higher than in control $(p<$ 0.05). However, serum levels of CLDN5, OCLN, and ZO-1 had no difference between ICH group and control groups $(p>0.05)$. Our data revealed that circulating TJs increased in CSF but not in serum of patients suffering from $\mathrm{ICH}$.
We did not find significant differences of CLDN5/OCLN or CLDN5/ZO-1 index (both in serum and in CSF) between ICH and controls $(p>0.05)$ (Table 3$)$.

3.3. Correlations among the Clinical Parameters and Circulating TJs Levels and BBB Malfunction in the ICH Patients. A Spearman rank correlation was used to analyze the correlations among circulating CLDN5, OCLN, and ZO-1 and the conventional biomarkers known to be associated with the $\mathrm{BBB}$ integrity (BBB ratio, $\mathrm{ALB}_{\mathrm{CSF}}$, and $\mathrm{WBC}_{\mathrm{CSF}}$ ) (Table 4 and Figure 1). In the ICH group, the CLDN5 $5_{\mathrm{CSF}}, \mathrm{OCLN}_{\mathrm{CSF}}$, and ZO- $1_{\mathrm{CSF}}$ were positively associated with $\mathrm{ALB}_{\mathrm{CSF}}(r=0.560$, $p=0.008 ; r=0.522, p=0.013$; and $r=0.604, p=0.003$, resp.) and $\mathrm{BBB}$ ratio $(r=0.588, p=0.005 ; r=0.588, p=$ 0.004 ; and $r=0.596, p=0.003$, resp.). No relationship was found between CSF TJs and $\mathrm{WBC}_{\mathrm{CSF}}(p>0.05)$, indicating that the inflammatory status may not affect the $\mathrm{BBB}$ integrity. The ratio of CLDN5/ZO-1 was positively associated with BBB ratio $(r=0.481, p=0.023)$ and $\mathrm{ALB}_{\mathrm{CSF}}(r=0.504, p=$ $0.017)$. However, no relationship was found between serum TJs concentrations and the BBB conventional biomarkers $(p>0.05)$. In addition, no relationship was found between circulating TJs and area of hemorrhage $(p>0.05)$. Our data revealed that the efficiency of concentrations of CLDN $5_{\mathrm{CSF}}$, OCLN $\mathrm{CSF}_{\mathrm{C}}$, and ZO-1 ${ }_{\mathrm{CSF}}$ was higher than serum TJs and other conventional biomarkers in reflecting $\mathrm{BBB}$ integrity.

3.4. CSF VEGF and MMP-9 Levels in Patients with ICH and the Controls. We further analyzed the mechanism inducing CLDN5, OCLN, and ZO-1 increased in CSF that was observed in $\mathrm{ICH}$ group. $\mathrm{VEGF}_{\mathrm{CSF}}$ and $\mathrm{MMP}-9_{\mathrm{CSF}}$ were measured in $\mathrm{ICH}$ patients and the controls. Our data found that $\mathrm{VEGF}_{\mathrm{CSF}}$ and MMP-9 ${ }_{\mathrm{CSF}}$ were significantly higher than 


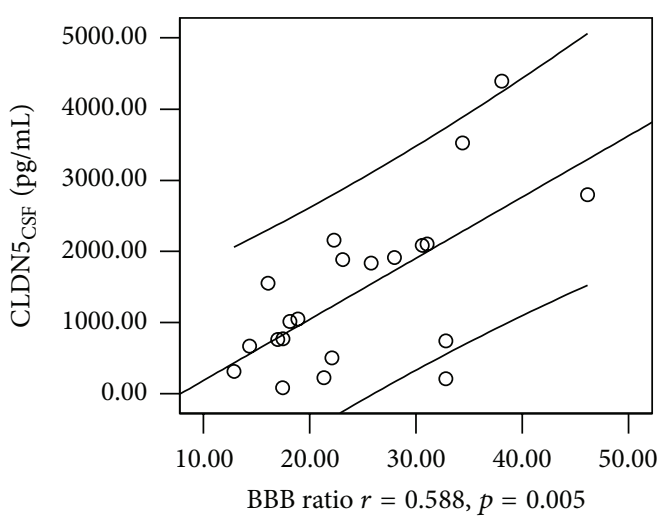

(a)

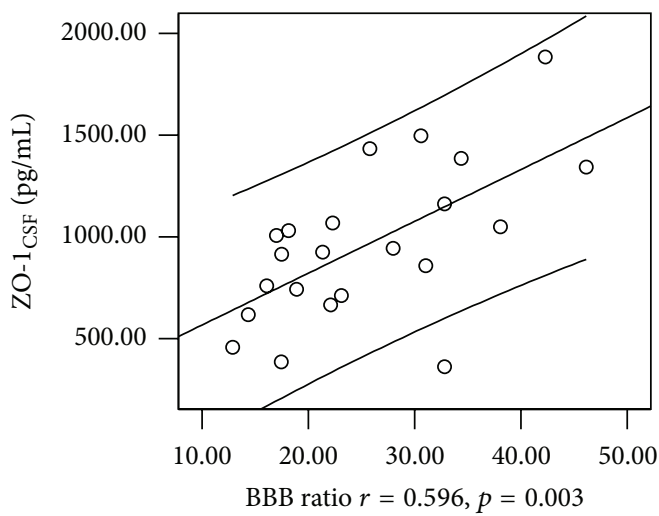

(c)

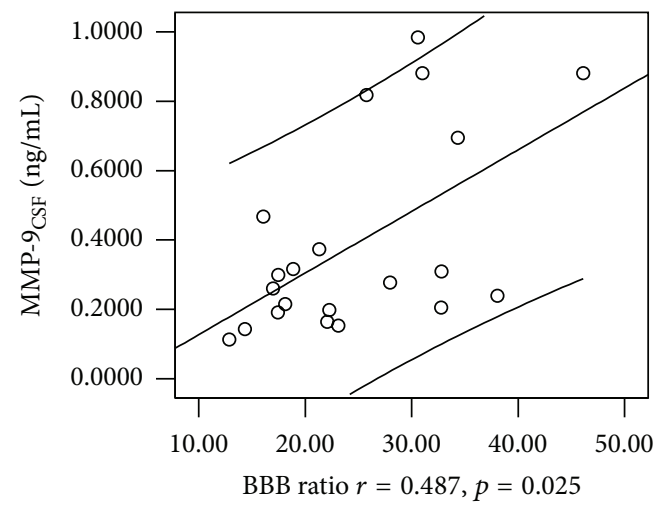

(e)

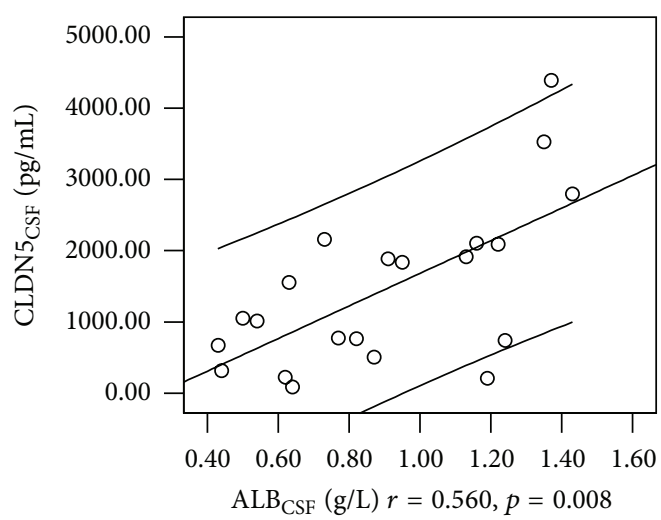

(g)

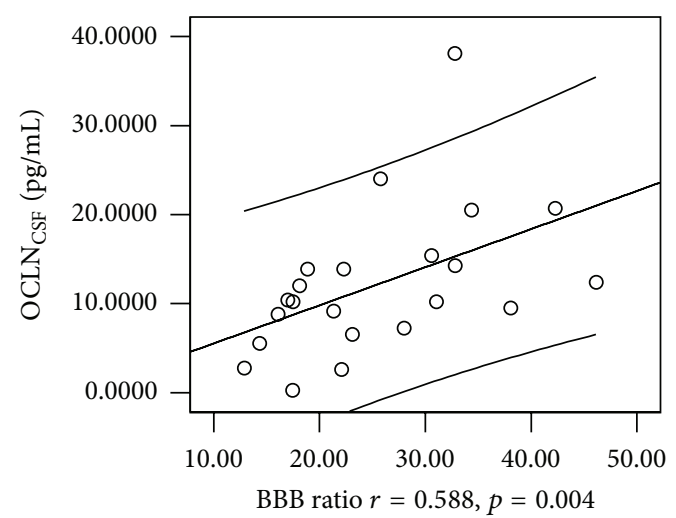

(b)

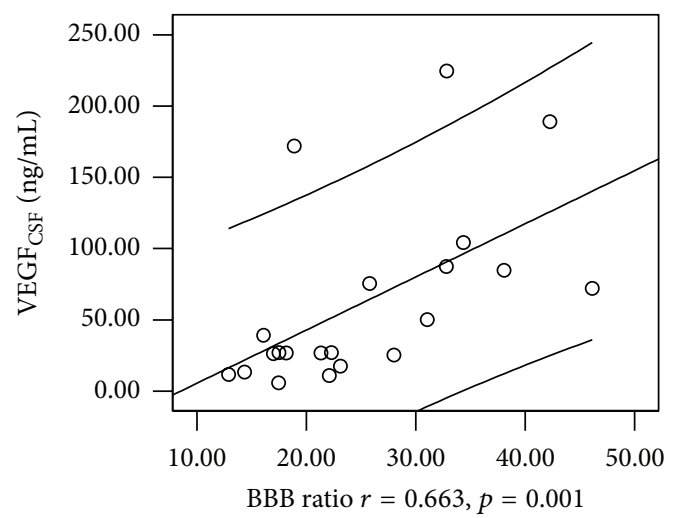

(d)

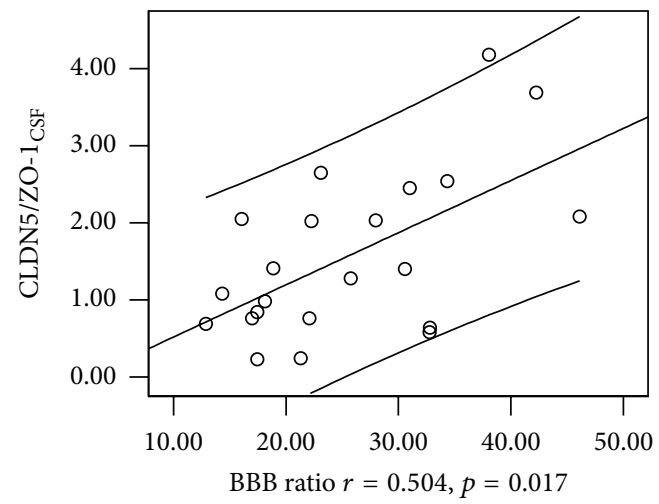

(f)

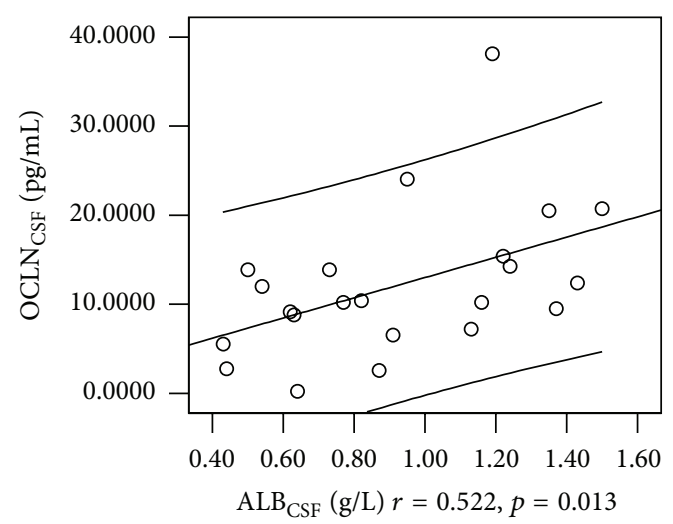

(h)

FIgURE 1: Continued. 


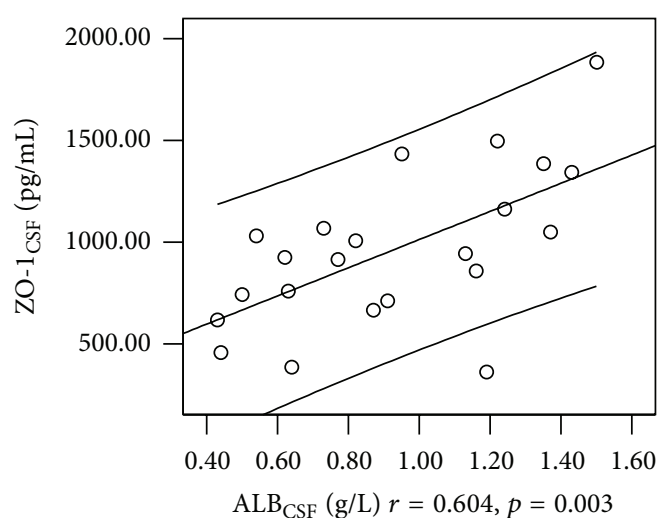

(i)

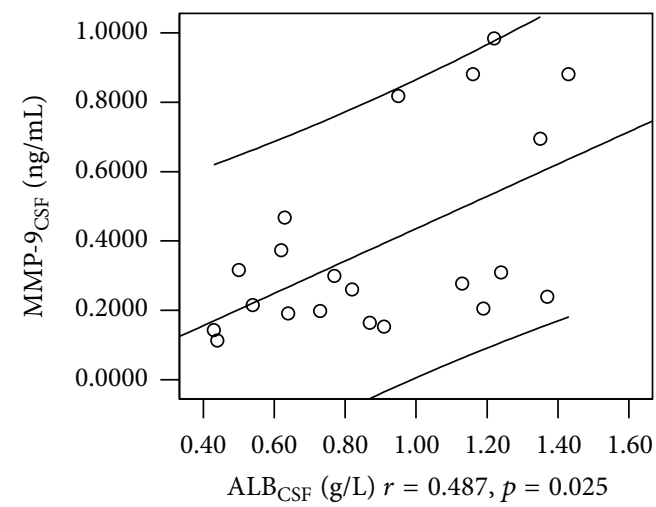

(k)

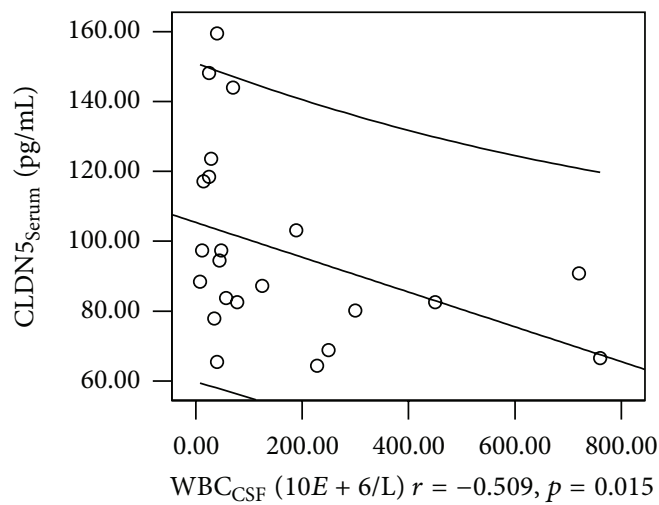

(m)

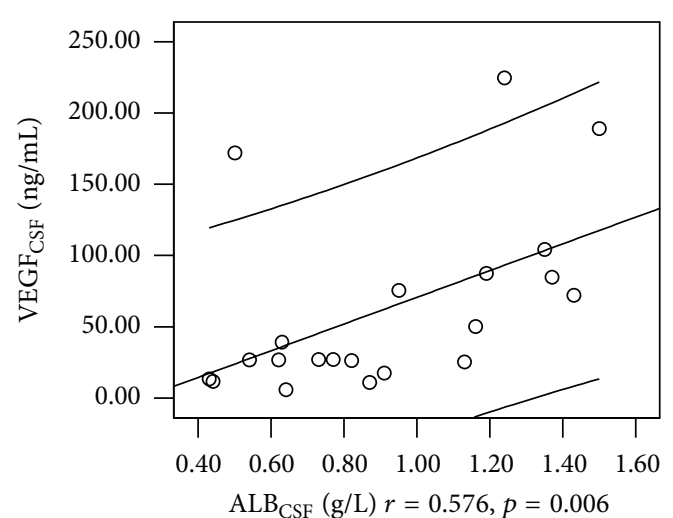

(j)

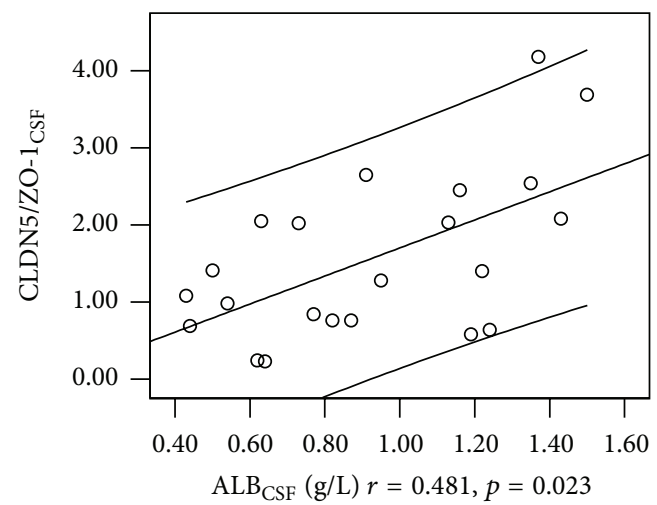

(l)

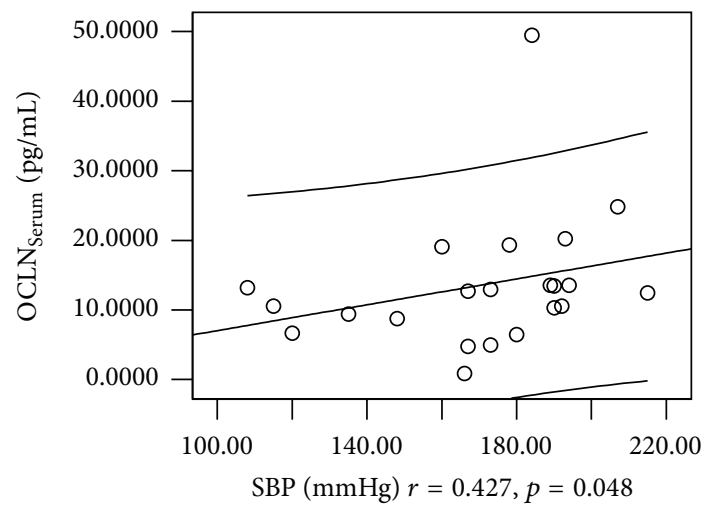

(n)

FIGURE 1: Correlations between parameters: positive correlations were found between BBB ratio and CLDN5 ${ }_{\mathrm{CSF}}(\mathrm{a}), \mathrm{BBB}$ ratio and OCLD $\mathrm{CSF}_{\mathrm{C}}$ (b), BBB ratio and $\mathrm{ZO}-1_{\mathrm{CSF}}$ (c), BBB ratio and $\mathrm{MMP}-9_{\mathrm{CSF}}(\mathrm{d}), \mathrm{BBB}$ ratio and $\mathrm{VEGF}_{\mathrm{CSF}}$ (e), BBB ratio and CLDN5 $5_{\mathrm{CSF}} / \mathrm{ZO}_{\mathrm{CO}} 1_{\mathrm{CSF}}(\mathrm{f}), \mathrm{ALB}_{\mathrm{CSF}}$ and $C L D N 5_{C S F}(\mathrm{~g}), \mathrm{ALB}_{\mathrm{CSF}}$ and $\mathrm{OCLD}_{\mathrm{CSF}}(\mathrm{h}), \mathrm{ALB}_{\mathrm{CSF}}$ and $\mathrm{ZO}-1_{\mathrm{CSF}}(\mathrm{i}), \mathrm{ALB}_{\mathrm{CSF}}$ and $\mathrm{MMP}-9_{\mathrm{CSF}}(\mathrm{j}), \mathrm{ALB}_{\mathrm{CSF}}$ and VEGF $\mathrm{CSF}_{\mathrm{C}}(\mathrm{k}), \mathrm{ALB}_{\mathrm{CSF}}$ and $\mathrm{CLDN}_{\mathrm{CSF}} / \mathrm{ZO}-1_{\mathrm{CSF}}(\mathrm{l})$, and SBP and $\mathrm{OCLN}_{\text {Serum }}(\mathrm{n})$. Negative correlation was found between $\mathrm{WBC}_{\mathrm{CSF}}$ and CLDN5 $5_{\text {Serum }}(\mathrm{m})$.

those in control $(p<0.05)$. VEGF $\mathrm{CSF}$ was positively associated with the $\mathrm{BBB}$ ratio $(r=0.663, p=0.001)$, while MMP-9 ${ }_{\mathrm{CSF}}$ was positively related to $\mathrm{BBB}$ ratio and $\mathrm{ALB}_{\mathrm{CSF}}$ $(r=0.487, p<0.05)$ (Tables 3 and 4$)$.

3.5. Diagnostic Significance of Circulating TJs in ICH. Diagnostic value of TJs levels in mirroring the BBB integrity was also evaluated. The sensitivities, specificities, positive predictive value (PPV), and negative predictive value (NPV) of circulating TJs in ICH diagnosis were shown in Table 5. Our data revealed that CSF levels of TJs had higher area under curve (AUC) and high sensitivity and specificity compared to the other conventional biomarkers studied. The sensitivity of $\mathrm{CLDN} 5_{\mathrm{CSF}}$ was $81.8 \%$, and the specificity was $94.1 \%$. The PPV of CLDN5 ${ }_{\text {CSF }}$ was $94.74 \%$ and NPV was $80.0 \%$. The

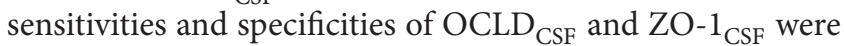
$95.5 \%$ versus $81.8 \%$ and $94.0 \%$ versus $94.0 \%$, respectively. The PPV of OCLD $\mathrm{CSF}_{\mathrm{C}}$ and $\mathrm{ZO}-1_{\mathrm{CSF}}$ were $95.5 \%$ versus $100 \%$ and 
TABLE 2: General characters of patients with intracranial hemorrhage and the controls.

\begin{tabular}{|c|c|c|}
\hline & Intracranial hemorrhage & Controls \\
\hline Age (yrs) & $55.05(49.18-60.91)$ & $23.88(14.70-33.06)$ \\
\hline $\mathrm{M} / \mathrm{F}$ & $12 / 10$ & $14 / 3$ \\
\hline SBP (mmHg) & $175.5(157.00-190.50)^{* *}$ & $121.00(100.50-133.00)$ \\
\hline DBP (mmHg) & $104.50(94.50-111.25)^{* *}$ & $70.00(66.50-82.00)$ \\
\hline $\mathrm{WBC}_{\text {Blood }}(10 E+9 / \mathrm{L})$ & $11.94(10.04-15.11)^{* *}$ & $7.61(5.93-11.04)$ \\
\hline $\mathrm{RBC}_{\text {Blood }}(10 E+12 / \mathrm{L})$ & $4.14(3.80-4.48)$ & $4.51(4.27-4.75)$ \\
\hline $\mathrm{Hb}_{\text {Blood }}(\mathrm{g} / \mathrm{L})$ & $123.95(115.29-132.63)$ & $128.06(118.76-137.35)$ \\
\hline $\operatorname{PLT}_{\text {Blood }}(10 E+9 / \mathrm{L})$ & $193.50(143.00-246.00)$ & $239.00(169.00-313.00)$ \\
\hline $\mathrm{LDH}_{\text {Serum }}(\mathrm{U} / \mathrm{L})$ & 247.14 (215.16-279.11) & $201.29(166.33-236.26)$ \\
\hline $\mathrm{AST}_{\text {Serum }}(\mathrm{U} / \mathrm{L})$ & $47.50(30.00-88.00)$ & $26.00(24.00-44.00)$ \\
\hline $\operatorname{ALT}_{\text {Serum }}(\mathrm{U} / \mathrm{L})$ & $38.00(19.00-90.00)^{*}$ & $21.00(15.00-33.00)$ \\
\hline $\mathrm{GGT}_{\text {Serum }}(\mathrm{U} / \mathrm{L})$ & $52.50(23.00-88.00)^{* *}$ & $17.00(12.00-24.00)$ \\
\hline $\operatorname{ALP}_{\text {Serum }}(\mathrm{U} / \mathrm{L})$ & $73.50(56.00-87.00)$ & $90.00(54.00-154.00)$ \\
\hline $\mathrm{CHE}_{\text {Serum }}(\mathrm{U} / \mathrm{L})$ & $5.85(4.90-6.81)^{*}$ & $7.16(6.41-7.91)$ \\
\hline $\mathrm{TP}_{\text {Serum }}(\mathrm{g} / \mathrm{L})$ & $65.71(61.68-69.74)$ & $67.50(64.19-70.81)$ \\
\hline $\mathrm{ALB}_{\text {Serum }}(\mathrm{g} / \mathrm{L})$ & $36.36(34.09-38.63)^{*}$ & $39.35(37.90-40.81)$ \\
\hline $\mathrm{Glu}_{\mathrm{CSF}}(\mathrm{mmol} / \mathrm{L})$ & $3.93(2.98-4.26)$ & $3.52(3.31-4.16)$ \\
\hline $\mathrm{Cl}_{\mathrm{CSF}}(\mathrm{mmol} / \mathrm{L})$ & $121.17(118.68-123.65)^{*}$ & $125.96(122.75-129.17)$ \\
\hline $\operatorname{ALB}_{\mathrm{CSF}}(\mathrm{g} / \mathrm{L})$ & $0.93(0.78-1.08)^{* *}$ & $0.43(0.30-0.55)$ \\
\hline $\mathrm{WBC}_{\mathrm{CSF}}(10 E+6 / \mathrm{L})$ & $52.50(28.00-233.50)^{* *}$ & $11.00(4.50-41.50)$ \\
\hline $\mathrm{BBB}$ ratio & $22.68(17.46-32.79)^{* *}$ & $9.69(6.27-13.23)$ \\
\hline
\end{tabular}

M: male; F: female; SBP: systolic blood pressure; DBP: diastolic blood pressure; CSF: cerebrospinal fluid; WBC: white blood cell; RBC: red blood cell; Hb: hemoglobin; PLT: platelet; LDH: L-lactate dehydrogenase; AST: aspartate aminotransferase; ALT: alanine aminotransferase; GGT: gamma-glutamyl transpeptidase; ALP: alkaline phosphatase; $\mathrm{CHE}$ : cholinesterase; TP: total protein; Alb: albumin; GLB: globulin; Glu: glucose; $\mathrm{Cl}$ : $\mathrm{chlorine} \mathrm{BBB}$ ratio: $\mathrm{Alb} \mathrm{CSF} \times$ $1000 / \mathrm{Alb}_{\text {Serum }}$.

${ }^{*} p \leq 0.05$ and ${ }^{* *} p \leq 0.01$ when the intracranial hemorrhage group is compared with control.

TABLE 3: Circulating TJs and cytokines in patients with intracranial hemorrhage and the controls.

\begin{tabular}{lcc}
\hline & Intracranial hemorrhage & Controls \\
\hline CLDN5 $_{\mathrm{CSF}}(\mathrm{pg} / \mathrm{mL})$ & $1302.35(669.72-2103.04)^{* *}$ & $157.28(107.48-213.82)$ \\
$\mathrm{CLDN}_{\text {Serum }}(\mathrm{pg} / \mathrm{mL})$ & $89.62(80.18-117.07)^{* *}$ & $125.79(103.07-125.79)$ \\
$\mathrm{OCLN}_{\mathrm{CSF}}(\mathrm{pg} / \mathrm{mL})$ & $10.30(7.22-14.26)^{* *}$ & $0.55(0.39-1.48)$ \\
$\mathrm{OCLN}_{\text {Serum }}(\mathrm{pg} / \mathrm{mL})$ & $12.56(8.75-13.54)$ & $10.95(9.63-10.95)$ \\
$\mathrm{ZO}-1_{\mathrm{CSF}}(\mathrm{pg} / \mathrm{mL})$ & $934.46(712.03-1161.35)^{* *}$ & $181.08(138.46-214.08)$ \\
$\mathrm{ZO}-1_{\text {Serum }}(\mathrm{pg} / \mathrm{mL})$ & $2007.96(1506.78-2647.24)^{* *}$ & $2173.48(1678.81-2173.48)$ \\
$\mathrm{CLDN5}_{\mathrm{CSF}} / \mathrm{OCLN}$ & $145.55(75.62-225.66)$ & $268.65(116.65-452.29)$ \\
$\mathrm{CLDN}_{\text {Serum }} / \mathrm{OCLN}$ & $7.77(6.24-12.02)$ & $11.48(10.70-13.26)$ \\
$\mathrm{CLDN}_{\mathrm{CSF}} / \mathrm{ZO}-1_{\mathrm{CSF}}$ & $1.34(0.76-2.08)$ & $0.93(0.57-1.39)$ \\
$\mathrm{CLDN}_{\text {Serum }} / \mathrm{ZO}-1_{\text {Serum }}$ & $0.0489(0.0413-0.0587)$ & $0.0579(0.0403-0.0579)$ \\
$\mathrm{VEGF}_{\mathrm{CSF}}(\mathrm{ng} / \mathrm{mL})$ & $33.16(25.42-87.43)^{* *}$ & $9.21(8.38-10.03)$ \\
MMP-9 $_{\mathrm{CSF}}(\mathrm{ng} / \mathrm{mL})$ & $0.29(0.20-0.69)^{* *}$ & $0.10(0.09-0.13)$ \\
\hline
\end{tabular}

CLDN5 $_{\text {Serum }}$ : serum Claudin-5; OCLN Serum $_{\text {: serum Occludin; ZO-1 }}$ serum: serum ZO-1; CSF: cerebrospinal fluid; CLDN5 CSF $_{\text {Claudin-5 in CSF; OCLN }}$ CSF: OCLN in CSF; ZO-1 ${ }_{C S F}$ : ZO-1 in CSF; VEGF: vascular endothelial growth factor; MMP-9: metalloproteinases.

${ }^{* *} p \leq 0.01$ when the intracranial hemorrhage group is compared with control.

NPV was $93.8 \%$ versus $85.0 \%$. This trend seems to be not existing in the controls. On the contrary, serum levels of TJs had higher AUC and high sensitivity and specificity in control group when compared to the patients with $\mathrm{ICH}$ (data not shown). With respect to the $\mathrm{VEGF}_{\mathrm{CSF}}$ and $\mathrm{MMP}-9_{\mathrm{CSF}}$, they had high specificities and sensitivities. Collectively, our data showed that TJs in CSF have high sensitivity and specificity in diagnosis of ICH.
3.6. Principal Component Analysis (PCA) and Hierarchical Clustering of Candidate Parameters. To identify a TJs profile that may provide a greater accuracy of class prediction than a single biomarker, we used the principal component analysis (PCA) (Figure 2) to choose a panel with the greatest accuracy of class prediction and the smallest misclassification error. PCA extracted four important principal components with eigenvalues $>1$, which explained $81.76 \%$ of total variance 


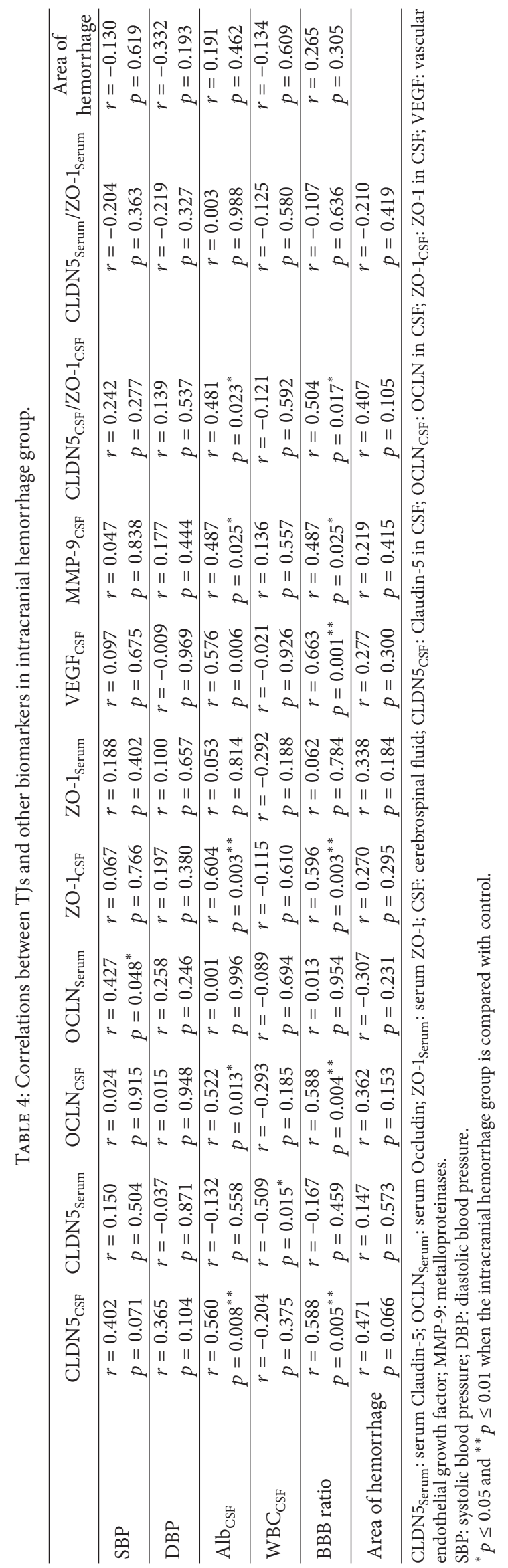


TABLE 5: Receiver operating characteristic curve analysis of the intracranial hemorrhage group.

\begin{tabular}{|c|c|c|c|c|c|c|c|}
\hline & AUC & $p$ & Cut-off value & Sensitivity & Specificity & PPV & NPV \\
\hline $\mathrm{ZO}-\mathrm{1}_{\mathrm{CSF}}(\mathrm{pg} / \mathrm{mL})$ & 0.992 & 0.000 & 374.21 & 95.50 & 94.10 & 95.50 & 94.10 \\
\hline $\operatorname{OCLN}_{\mathrm{CSF}}(\mathrm{pg} / \mathrm{mL})$ & 0.960 & 0.000 & 2.19 & 95.50 & 94.10 & 95.50 & 94.10 \\
\hline $\mathrm{CLDN} 5_{\mathrm{CSF}}(\mathrm{pg} / \mathrm{mL})$ & 0.930 & 0.000 & 409.18 & 81.80 & 94.10 & 94.74 & 80.00 \\
\hline MMP-9 $_{\mathrm{CSF}}(\mathrm{ng} / \mathrm{mL})$ & 0.930 & 0.000 & 0.19 & 81.80 & 94.10 & 94.70 & 80.00 \\
\hline $\mathrm{SBP}(\mathrm{mmHg})$ & 0.898 & 0.000 & 159.50 & 77.30 & 94.10 & 94.70 & 80.00 \\
\hline $\operatorname{ALB}_{\mathrm{CSF}}(\mathrm{g} / \mathrm{L})$ & 0.896 & 0.000 & 0.50 & 90.90 & 82.40 & 87.00 & 87.50 \\
\hline $\mathrm{DBP}(\mathrm{mmHg})$ & 0.893 & 0.000 & 95.00 & 77.30 & 94.10 & 94.40 & 76.20 \\
\hline $\operatorname{VEGF}_{\mathrm{CSF}}(\mathrm{ng} / \mathrm{mL})$ & 0.869 & 0.000 & 11.28 & 90.90 & 82.40 & 87.00 & 87.50 \\
\hline $\mathrm{WBC}_{\mathrm{CSF}}(10 E+6 / \mathrm{L})$ & 0.837 & 0.000 & 22.50 & 86.40 & 64.70 & 76.00 & 78.60 \\
\hline $\operatorname{OCLN}_{\text {Serum }}(\mathrm{pg} / \mathrm{mL})$ & 0.567 & 0.479 & 11.72 & 54.50 & 88.20 & 86.70 & 62.50 \\
\hline $\mathrm{ZO}-1_{\text {Serum }}(\mathrm{pg} / \mathrm{mL})$ & 0.432 & 0.470 & 2344.28 & 36.40 & 82.40 & 72.70 & 50.00 \\
\hline $\mathrm{CLDN}_{\text {Serum }}(\mathrm{pg} / \mathrm{mL})$ & 0.251 & 0.008 & 68.25 & 86.40 & 11.80 & 90.50 & 83.30 \\
\hline
\end{tabular}

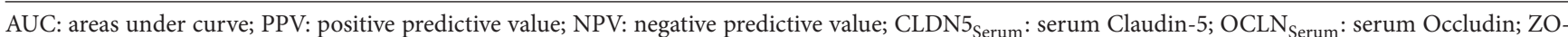
$1_{\text {Serum }}$ : serum ZO-1; CSF: cerebrospinal fluid; CLDN5 ${ }_{\mathrm{CSF}}$ : Claudin-5 in CSF; OCLN $\mathrm{CSF}_{\text {: }}$ OCLN in CSF; ZO-1 $1_{\mathrm{CSF}}$ : ZO-1 in CSF; VEGF: vascular endothelial growth factor; MMP-9: metalloproteinases; SBP: systolic blood pressure; DBP: diastolic blood pressure.

TABLE 6: Loading scores of variables on the first three significant principal components.

\begin{tabular}{|c|c|c|c|c|}
\hline & Component 1 & Component 2 & Component 3 & Component 4 \\
\hline $\mathrm{ZO}-\mathrm{1}_{\mathrm{CSF}}(\mathrm{pg} / \mathrm{mL})$ & 0.882 & 0.041 & 0.136 & 0.058 \\
\hline MMP-9 ${ }_{\mathrm{CSF}}(\mathrm{ng} / \mathrm{mL})$ & 0.869 & -0.104 & 0.189 & 0.185 \\
\hline $\mathrm{CLDN}_{\mathrm{CSF}}(\mathrm{pg} / \mathrm{mL})$ & 0.847 & 0.114 & 0.090 & 0.181 \\
\hline $\operatorname{ALB}_{C S F}(g / L)$ & 0.750 & 0.086 & 0.464 & -0.017 \\
\hline $\operatorname{VEGF}_{\mathrm{CSF}}(\mathrm{ng} / \mathrm{mL})$ & 0.582 & -0.307 & -0.178 & -0.224 \\
\hline $\mathrm{OCLN}_{\mathrm{CSF}}(\mathrm{pg} / \mathrm{mL})$ & 0.457 & -0.150 & 0.383 & -0.565 \\
\hline $\mathrm{ZO}-1_{\text {Serum }}(\mathrm{pg} / \mathrm{mL})$ & 0.356 & 0.506 & -0.503 & 0.028 \\
\hline CLDN5 $5_{\text {Serum }}(\mathrm{pg} / \mathrm{mL})$ & 0.355 & 0.278 & -0.801 & -0.061 \\
\hline $\mathrm{OCLN}_{\text {Serum }}(\mathrm{pg} / \mathrm{mL})$ & 0.279 & 0.690 & -0.238 & 0.309 \\
\hline $\mathrm{WBC}_{\mathrm{CSF}}(10 E+6 / \mathrm{L})$ & -0.184 & -0.005 & 0.458 & 0.743 \\
\hline $\mathrm{DBP}(\mathrm{mmHg})$ & -0.204 & 0.756 & 0.469 & -0.194 \\
\hline SBP (mmHg) & -0.221 & 0.803 & 0.318 & -0.269 \\
\hline
\end{tabular}

Bold values indicate strong and moderate loadings: Component 1 has strong positive loadings on $\mathrm{ZO}-1_{\mathrm{CSF}}, \mathrm{MMP}_{\mathrm{CSF}}$, $\mathrm{CLDN}_{\mathrm{CSF}}, \mathrm{Alb}_{\mathrm{CSF}}$, VEGF $\mathrm{CSF}$, and

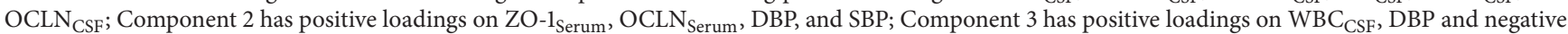
loadings on $\mathrm{ZO}-1_{\text {Serum }}$, $\mathrm{CLDN}_{\text {Serum }}$; Component 4 has positive loadings on $\mathrm{WBC}_{\mathrm{CSF}}$ and negative loadings on OCLN $\mathrm{CSF}_{\text {. }}$.

in the data set. The first model showed strong positive loadings $(>0.75)$ for $\mathrm{ALB}_{\mathrm{CSF}}, \mathrm{CLDN} 5_{\mathrm{CSF}}, \mathrm{OCLD}_{\mathrm{CSF}}, \mathrm{ZO}-1_{\mathrm{CSF}}$, and MMP-9 $\mathrm{CSF}$. The second model included $\mathrm{OCLN}_{\mathrm{Serum}}$, ZO- $1_{\text {Serum }}$, DBP, and SBP. The third model included $\mathrm{WBC}_{\mathrm{CSF}}$ and DBP. However, the AUC value of Component 1 was 0.928 , and the sensitivity was $81.8 \%$, and the specificity was $94.1 \%$, not higher than the single parameter from the overall level (Tables 6 and 7). To find out whether the difference is due to the small simple size, further study with larger sample size is needed.

\section{Discussion}

The need for new therapeutic approaches for ICH has prompted a search for the molecular and cellular mechanisms underlying early or delayed brain damage after ICH [32]. It is difficult to assess the importance of secondary $\mathrm{BBB}$ disruption following $\mathrm{ICH}$ that contributed to brain injury [33]. Blood/blood vessels breakdown products may be released in CSF following $\mathrm{ICH}$, where CSF circulation plays a major role in clearing these products [34]. Therefore, the change of proteins in CSF is valuable in reflecting pathogenic status and prediction of ICH's outcome. In addition, circulating biomarkers are easily measurable, accurate, and costeffective, making them more accessible in clinic. However, up to date, no circulating biomarkers mirror the degree of brain injury following ICH, nor have biomarkers predicting ICH's outcome been incorporated into routine clinical work [35].

In previous study, the observed $\mathrm{BBB}$ opening after $\mathrm{SAH}$ was related to the damage of tight junction [15]. The molecules released into the circulation occur during brain ischemia [21], indicating disassembly of TJs, and then disrupt the integrity of the BBB. Loss of ZO-1 and OCLN from cerebral vascular endothelium was also observed during CNS inflammation [36]. Supporting the point, we found that $\mathrm{TJs}_{\mathrm{CSF}}$ were significantly higher in patients with $\mathrm{ICH}$ than 
TABLE 7: Receiver operating characteristic curve analysis of the components.

\begin{tabular}{|c|c|c|c|c|c|c|c|}
\hline & AUC & $p$ & Cut-off value & Sensitivity & Specificity & PPV & NPV \\
\hline Component 1 & 0.928 & 0.000 & -0.708 & 81.8 & 94.1 & 94.7 & 80.0 \\
\hline Component 2 & 0.794 & 0.002 & -0.559 & 72.7 & 88.2 & 88.2 & 68.2 \\
\hline Component 3 & 0.939 & 0.000 & -1.005 & 86.4 & 94.1 & 95.0 & 84.2 \\
\hline Component 4 & 0.317 & 0.041 & 0.827 & 22.7 & 94.1 & 85.7 & 50.0 \\
\hline
\end{tabular}

AUC: areas under curve; PPV: positive predictive value; NPV: negative predictive value.

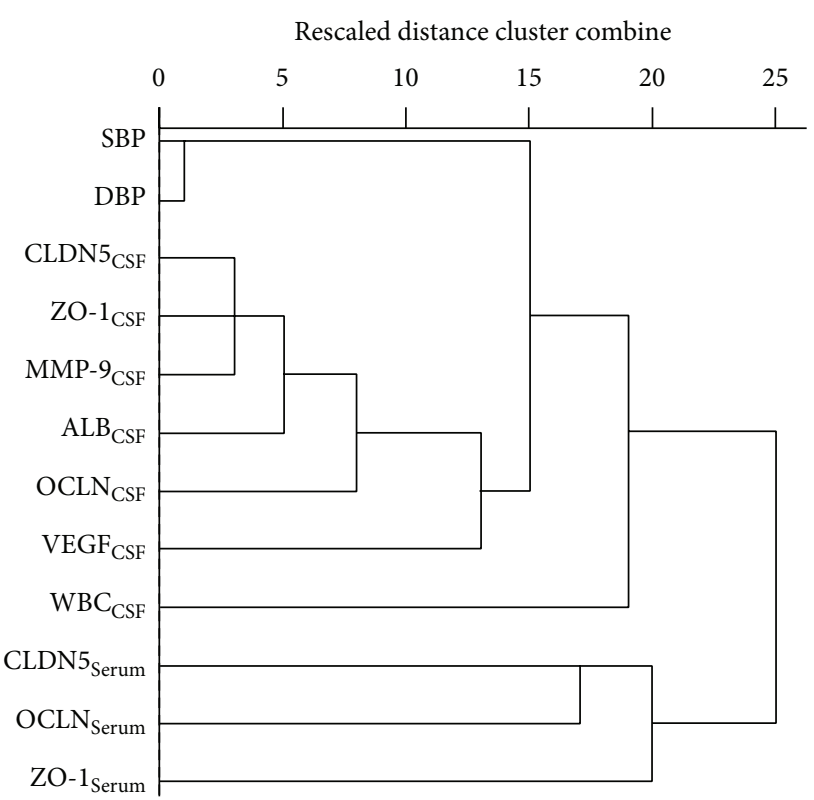

Figure 2: Dendrogram based on hierarchical agglomerative clustering of sampling stations using single linkage method. Parameters were classified into 3 main categories. The $\mathrm{CLDN} 5_{\mathrm{CSF}}$, ZO- $1_{\mathrm{CSF}}, \mathrm{MMP}-9_{\mathrm{CSF}}, \mathrm{ALB}_{\mathrm{CSF}}, \mathrm{OCLN}_{\mathrm{CSF}}$, and $\mathrm{VEGF}_{\mathrm{CSF}}$ were gathered together; the CLDN5 $5_{\text {Serum }}, \mathrm{OCLN}_{\text {Serum }}$, and $\mathrm{ZO}-1_{\text {Serum }}$ were gathered together; the SBP and DBP were gathered together.

the individuals who had no BBB damage. Together with a strong correlation existing between TJs concentration in CSF and the $\mathrm{BBB}$ ratio in patients with $\mathrm{ICH}$, our data demonstrate the levels of $\mathrm{TJs}_{\mathrm{CSF}}$ could be the potential biomarker for mirroring the extent of $\mathrm{BBB}$ opening in patients with $\mathrm{ICH}$. In clinical practice, blood biomarkers are the first choice as many of them assist in rapid diagnosis, therapeutic decisions, and easier collection. Unfortunately, we could not find significant elevation of serum TJs nor correlation between CSF and serum's TJs. There may be two reasons to explain; the first one may be due to too small sample size in our study; statistical significance may be gained in a larger cohort. But there may be another reason: no correlation existed between CSF and serum. BBB breakdown is a local event of CNS; TJs elevated in CSF have difficulty inducing significant elevation of TJs in serum, especially considering the CSF volume versus serum volume. Further study is needed to elucidate the details. In conclusion, CSF biomarkers may have high sensitivity and specificity in reflecting CNS pathologic status, which is supported by our data that CSF levels of TJs had higher AUC and high sensitivity and specificity compared to serum TJs and other conventional serum biomarkers studied.

$\mathrm{BBB}$ disruption increases cerebrovascular permeability, allowing the entrance of leukocytes into the brain parenchyma which can in turn cause edema formation [9]. Higher $\mathrm{WBC}_{\mathrm{CSF}}$ in $\mathrm{ICH}$ patients demonstrated that damaged $\mathrm{BBB}$ integrity leads to peripheral WBC transferred into the CNS. The TJs' completeness in BBB strictly depends on signals provided by the CNS microenvironment [37]. Increased permeability of the $\mathrm{BBB}$ can be caused by disruption of the extracellular matrix [38]. There is evidence that MMPs are increased after ICH [22] and involved in disruption of tight junctions, leading to increased BBB permeability and vasogenic brain edema [39]. Neutrophils are very important sources of MMP-9 after ICH [40]. In our study, significantly higher infiltrating leucocytes may contribute to higher level of MMP-9 in CSF after ICH, which should be a major source of MMP-9 in CSF [41]. MMP-9 degraded TJs and is associated with the disruption of OCLN and CLDN5 in brain endothelial cells [42-44]. Elevated MMP-9 ${ }_{\mathrm{CSF}}$ change the permeability of the $\mathrm{BBB}$, participating in the opening of the $\mathrm{BBB}$ in $\mathrm{ICH}$ patients $[45,46]$. Our data revealed that $\mathrm{ICH}$ induces $\mathrm{BBB}$ hyperpermeability through permeated neutrophils that released abundant MMP-9 in CSF, then, leading to TJs release into CSF.

Both BBB disruption and consequent vasogenic edema determine the clinical course of $\mathrm{ICH}[16,47]$. It is vital to understand the mechanisms underlying the mechanism of edema formation in $\mathrm{ICH}[33,48]$. VEGF is a factor that increases permeability of the endothelium [49]. Studies also show that VEGF disrupts TJs, induces breakdown of the BBB, and causes edema [50]. High permeability of blood vessel leads to leakage of large molecule and blood products into the vessel or perivascular space and induces serum proteins extravasated freely in the brain, forming vasogenic edema. In our study, $\mathrm{VEGF}_{\mathrm{CSF}}$ in $\mathrm{ICH}$ patients is significantly higher than that in control, which is positively associated with the $\mathrm{BBB}$ ratio, revealing that higher concentration of $\mathrm{VEGF}_{\mathrm{CSF}}$ contributes to the BBB permeability in ICH. VEGF perturbs TJ integrity by decreasing OCLN and ZO-1 expression and causing CLDN5 and ZO-1 protein disruption [50]. Positive associations were observed between BBB disruption and $\mathrm{VEGF}_{\mathrm{CSF}}$, indicating that higher $\mathrm{VEGF}_{\mathrm{CSF}}$ may be a crucial factor in $\mathrm{BBB}$ high permeability in $\mathrm{ICH}$ [51].

In some cases, the diameter of brain parenchyma blood vessels affected by $\mathrm{ICH}$ is too small to be observed by conventional imaging techniques. A recently proposed model of cerebral microscopic hemorrhage suggested that transient loss of endothelial barrier function might be an underlying 
process [26]. Hypertension, very high levels occurring in patients with ICH, can cause microaneurysms and small vessel wall damage and a gradual weakening of vascular integrity that eventually leads to rupture. Fluctuations in SBP as a result of impaired cerebral autoregulatory control in microvascular channels could promote hematoma expansion [52], but study also showed no association of blood pressure variability and hematoma growth [53], which is also observed in our study. Elevated blood pressure may cause endothelial dysfunction, leading to opening of the BBB [54]. To patients with microbleed or microvascular injury, circulating biomarker measurement may have some advantages in early diagnosis. Vascular damage induced by hypertension may be the initial cause of ICH and BBB dysfunction (with associated edema and leukocyte extravasation) is a secondary consequence [55].

Although early diagnosis and intervention may be paramount to improving patient prognosis [29], little is known about predictors for recurrence of primary ICH and particularly predictors for fatal recurrence [1]. MMP- ${ }_{\mathrm{CSF}}, \mathrm{VEGF}_{\mathrm{CSF}}$, and $\mathrm{TJs}_{\mathrm{CSF}}$ could be sensitive biomarkers as their expressions in some patients were upregulated just after ICH (data not shown). TJs have been considered attractive targets for transient breakdown of the BBB in therapies for various CNS disorders [13]. A panel of biomarkers may have far more discriminative power than any single biomarker alone to distinguish pathophysiological complications and brain damage following aSAH [31]. When we try to use the principal component analysis (PCA) to search a panel of biomarkers with the greatest accuracy of class prediction and the smallest misclassification error, the first model extracted was the $\mathrm{ALB}_{\mathrm{CSF}}, \mathrm{CLDN}_{\mathrm{CSF}}, \mathrm{OCLD} \mathrm{CSF}_{\mathrm{CF}}, \mathrm{ZO}-1_{\mathrm{CSF}}$, and MMP- $9_{\mathrm{CSF}}$, which could explain $81.76 \%$ of total variance in the data set. To find out whether the panel TJs in our study can reflect more accurately the BBB disruption and early brain injury after ICH than conventional biomarkers, larger sample size is needed.

The main limitation of TJs in CSF as the diagnostic biomarker is that LPs are not to be routinely done in some patients with ICH. Under this circumstance, circulating biomarkers and image detection should be carefully used according to patient's status. Another limitation of our study was that we could not measure the TJs at the different time points. Also, we have enrolled relatively small numbers of subjects that mainly have significantly large hematoma size. Our study will have better clinical significance if studying subject includes the patients with microbleeding; however, the patients' choice remains a challenge. Given that the CSF TJs serve diagnostic purposes for BBB disruption after ICH, further study will be needed to identify that the biomarkers could be translated into routine clinical practice. The sensitivity, specificity, PPV, and NPV for CSF TJs in diagnosis of ICH also need to be evaluated.

\section{Conflict of Interests}

The authors declare that they have no conflict of interests.

\section{Acknowledgments}

This work was supported by grants of the National Natural Science Foundation of China (NSFC) (31371333) and Guangdong Natural Science Foundation (nos. S2012030006289 and S2012030006289).

\section{References}

[1] C. J. van Asch, M. J. Luitse, G. J. Rinkel, I. van der Tweel, A. Algra, and C. J. Klijn, "Incidence, case fatality, and functional outcome of intracerebral haemorrhage over time, according to age, sex, and ethnic origin: a systematic review and metaanalysis," The Lancet Neurology, vol. 9, no. 2, pp. 167-176, 2010.

[2] C. E. Lovelock, A. Molyneux, and P. Rothwell, "Change in incidence and aetiology of intracerebral haemorrhage in Oxfordshire, UK, between 1981 and 2006: a population-based study," The Lancet Neurology, vol. 6, no. 6, pp. 487-493, 2007.

[3] O. G. Nilsson, A. Lindgren, L. Brandt, and H. Säveland, "Prediction of death in patients with primary intracerebral hemorrhage: a prospective study of a defined population," Journal of Neurosurgery, vol. 97, no. 3, pp. 531-536, 2002.

[4] K. Ohwaki, E. Yano, H. Nagashima, M. Hirata, T. Nakagomi, and A. Tamura, "Blood pressure management in acute intracerebral hemorrhage: relationship between elevated blood pressure and hematoma enlargement," Stroke, vol. 35, no. 6, pp. 1364-1367, 2004.

[5] J. Claassen, J. R. Carhuapoma, K. T. Kreiter, E. Y. Du, E. S. Connolly, and S. A. Mayer, "Global cerebral edema after subarachnoid hemorrhage: frequency, predictors, and impact on outcome," Stroke, vol. 33, no. 5, pp. 1225-1232, 2002.

[6] H. Arima, J. G. Wang, Y. Huang et al., "Significance of perihematomal edema in acute intracerebral hemorrhage: the INTERACT trial," Neurology, vol. 73, no. 23, pp. 1963-1968, 2009.

[7] G.-Y. Yang, A. L. Betz, T. L. Chenevert, J. A. Brunberg, and J. T. Hoff, "Experimental intracerebral hemorrhage: relationship between brain edema, blood flow, and blood-brain barrier permeability in rats," Journal of Neurosurgery, vol. 81, no. 1, pp. 93-102, 1994.

[8] D. Yang, R. A. Knight, Y. Han et al., "Statins protect the blood brain barrier acutely after experimental intracerebral hemorrhage," Journal of Behavioral and Brain Science, vol. 3, no. 1, pp. 100-106, 2013.

[9] R. F. Keep, J. Xiang, S. R. Ennis et al., "Blood-brain barrier function in intracerebral hemorrhage," Acta Neurochirurgica, Supplementum, vol. 105, pp. 73-77, 2008.

[10] Y. Lampl, O. Shmuilovich, J. Lockman, M. Sadeh, and M. Lorberboym, "Prognostic significance of blood brain barrier permeability in acute hemorrhagic stroke," Cerebrovascular Diseases, vol. 20, no. 6, pp. 433-437, 2005.

[11] U. Kniesel and H. Wolburg, "Tight junctions of the blood-brain barrier," Cellular and Molecular Neurobiology, vol. 20, no. 1, pp. 57-76, 2000.

[12] Y. Yang and G. A. Rosenberg, "Blood-brain barrier breakdown in acute and chronic cerebrovascular disease," Stroke, vol. 42, no. 11, pp. 3323-3328, 2011.

[13] T. Nitta, M. Hata, S. Gotoh et al., "Size-selective loosening of the blood-brain barrier in claudin-5-deficient mice," The Journal of Cell Biology, vol. 161, no. 3, pp. 653-660, 2003. 
[14] M. Ishiguro, K. Mishiro, Y. Fujiwara et al., "PhosphodiesteraseIII inhibitor prevents hemorrhagic transformation induced by focal cerebral ischemia in mice treated with tPA," PLOS ONE, vol. 5, no. 12, Article ID e15178, 2010.

[15] Z. Li, G. Liang, T. Ma et al., "Blood-brain barrier permeability change and regulation mechanism after subarachnoid hemorrhage," Metabolic Brain Disease, vol. 30, no. 2, pp. 597-603, 2015.

[16] M. Fujii, K. Duris, O. Altay, Y. Soejima, P. Sherchan, and J. H. Zhang, "Inhibition of Rho kinase by hydroxyfasudil attenuates brain edema after subarachnoid hemorrhage in rats," Neurochemistry International, vol. 60, no. 3, pp. 327-333, 2012.

[17] W. Zhou, M. Marinescu, and R. Veltkamp, "Only very early oxygen therapy attenuates posthemorrhagic edema formation and blood-brain barrier disruption in murine intracerebral hemorrhage," Neurocritical Care, vol. 22, no. 1, pp. 121-132, 2015.

[18] P. Delgado, J. A. Alvarez Sabin, E. Santamarina et al., "Plasma S100B level after acute spontaneous intracerebral hemorrhage," Stroke, vol. 37, no. 11, pp. 2837-2839, 2006.

[19] Y.-T. Tang, F. Jiang, L. Guo, M.-Y. Si, and X.-Y. Jiao, "Expression and significance of vascular endothelial growth factor A and $\mathrm{C}$ in leukemia central nervous system metastasis," Leukemia Research, vol. 37, no. 4, pp. 359-366, 2013.

[20] S. C. Thal, C. Luh, E.-V. Schaible et al., "Volatile anesthetics influence blood-brain barrier integrity by modulation of tight junction protein expression in traumatic brain injury," PLOS ONE, vol. 7, no. 12, Article ID e50752, 2012.

[21] R. Kazmierski, S. Michalak, A. Wencel-Warot, and W. L. Nowinski, "Serum tight-junction proteins predict hemorrhagic transformation in ischemic stroke patients," Neurology, vol. 79, no. 16, pp. 1677-1685, 2012.

[22] J. Alvarez-Sabín, P. Delgado, S. Abilleira et al., “Temporal profile of matrix metalloproteinases and their inhibitors after spontaneous intracerebral hemorrhage: relationship to clinical and radiological outcome," Stroke, vol. 35, no. 6, pp. 1316-1322, 2004.

[23] D. O. Bates, "Vascular endothelial growth factors and vascular permeability," Cardiovascular Research, vol. 87, no. 2, pp. 262271, 2010.

[24] J. Wang and S. Doré, "Inflammation after intracerebral hemorrhage," Journal of Cerebral Blood Flow and Metabolism, vol. 27, no. 5, pp. 894-908, 2007.

[25] M. Schrag, G. McAuley, J. Pomakian et al., "Correlation of hypointensities in susceptibility-weighted images to tissue histology in dementia patients with cerebral amyloid angiopathy: a postmortem MRI study," Acta Neuropathologica, vol. 119, no. 3, pp. 291-302, 2010.

[26] M. Fisher, S. French, P. Ji, and R. C. Kim, "Cerebral microbleeds in the elderly: a pathological analysis," Stroke, vol. 41, no. 12, pp. 2782-2785, 2010.

[27] J. A. Edlow, A. M. Malek, and C. S. Ogilvy, "Aneurysmal subarachnoid hemorrhage: update for emergency physicians," Journal of Emergency Medicine, vol. 34, no. 3, pp. 237-251, 2008.

[28] A. Brodbelt and M. Stoodley, "CSF pathways: a review," British Journal of Neurosurgery, vol. 21, no. 5, pp. 510-520, 2007.

[29] M. D. King, M. D. Laird, S. S. Ramesh et al., "Elucidating novel mechanisms of brain injury following subarachnoid hemorrhage: an emerging role for neuroproteomics," Neurosurgical Focus, vol. 28, no. 1, p. E10, 2010.

[30] M. Bulat and M. Klarica, "Recent insights into a new hydrodynamics of the cerebrospinal fluid," Brain Research Reviews, vol. 65, no. 2, pp. 99-112, 2011.
[31] R. Siman, N. Giovannone, N. Toraskar et al., "Evidence that a panel of neurodegeneration biomarkers predicts vasospasm, infarction, and outcome in aneurysmal subarachnoid hemorrhage," PLoS ONE, vol. 6, no. 12, Article ID e28938, 2011.

[32] E. Mracsko and R. Veltkamp, "Neuroinflammation after intracerebral hemorrhage," Frontiers in Cellular Neuroscience, vol. 8, article 388, 2014.

[33] G. A. Bateman and S. H. Siddique, "Cerebrospinal fluid absorption block at the vertex in chronic hydrocephalus: obstructed arachnoid granulations or elevated venous pressure?" Fluids and Barriers of the CNS, vol. 11, article 11, 2014.

[34] A. G. Kolias, J. Sen, and A. Belli, "Pathogenesis of cerebral vasospasm following aneurysmal subarachnoid hemorrhage: putative mechanisms and novel approaches," Journal of Neuroscience Research, vol. 87, no. 1, pp. 1-11, 2009.

[35] R. Senn, M. S. V. Elkind, J. Montaner, M. Christ-Crain, and M. Katan, "Potential role of blood biomarkers in the management of nontraumatic intracerebral hemorrhage," Cerebrovascular Diseases, vol. 38, no. 6, pp. 395-409, 2014.

[36] S. J. Bolton, D. C. Anthony, and V. H. Perry, "Loss of the tight junction proteins occludin and zonula occludens-1 from cerebral vascular endothelium during neutrophil-induced bloodbrain barrier breakdown in vivo," Neuroscience, vol. 86, no. 4, pp. 1245-1257, 1998.

[37] H. Wolburg, J. Neuhaus, U. Kniesel et al., "Modulation of tight junction structure in blood-brain barrier endothelial cells. Effects of tissue culture, second messengers and cocultured astrocytes," Journal of Cell Science, vol. 107, part 5, pp. 1347-1357, 1994.

[38] D. Knowland, A. Arac, K. J. Sekiguchi et al., "Stepwise recruitment of transcellular and paracellular pathways underlies blood-brain barrier breakdown in stroke," Neuron, vol. 82, no. 3, pp. 603-617, 2014.

[39] P. Ballabh, A. Braun, and M. Nedergaard, "The blood-brain barrier: an overview: structure, regulation, and clinical implications," Neurobiology of Disease, vol. 16, no. 1, pp. 1-13, 2004.

[40] I. Moxon-Emre and L. C. Schlichter, "Neutrophil depletion reduces blood-brain barrier breakdown, axon injury, and inflammation after intracerebral hemorrhage," Journal of $\mathrm{Neu}$ ropathology and Experimental Neurology, vol. 70, no. 3, pp. 218235, 2011.

[41] M. Xue and V. W. Yong, "Matrix metalloproteinases in intracerebral hemorrhage," Neurological Research, vol. 30, no. 8, pp. 775-782, 2008

[42] J. Liu, X. Jin, K. J. Liu, and W. Liu, "Matrix metalloproteinase2-mediated occludin degradation and caveolin-1-mediated claudin-5 redistribution contribute to blood-brain barrier damage in early ischemic stroke stage," Journal of Neuroscience, vol. 32, no. 9, pp. 3044-3057, 2012.

[43] Y. Yang and G. A. Rosenberg, "MMP-mediated disruption of claudin-5 in the blood-brain barrier of rat brain after cerebral ischemia," Methods in Molecular Biology, vol. 762, pp. 333-345, 2011.

[44] P. Balbuena, W. Li, and M. Ehrich, "Assessments of tight junction proteins occludin, claudin 5 and scaffold proteins $\mathrm{ZO1}$ and $\mathrm{ZO} 2$ in endothelial cells of the rat blood-brain barrier: cellular responses to neurotoxicants malathion and lead acetate," NeuroToxicology, vol. 32, no. 1, pp. 58-67, 2011.

[45] G. A. Rosenberg and Y. Yang, "Vasogenic edema due to tight junction disruption by matrix metalloproteinases in cerebral ischemia," Neurosurgical Focus, vol. 22, no. 5, article E4, 2007. 
[46] L. S. Machado, A. Kozak, A. Ergul, D. C. Hess, C. V. Borlongan, and S. C. Fagan, "Delayed minocycline inhibits ischemiaactivated matrix metalloproteinases 2 and 9 after experimental stroke," BMC Neuroscience, vol. 7, article 56, 2006.

[47] R. P. Ostrowski, A. R. Colohan, and J. H. Zhang, "Molecular mechanisms of early brain injury after subarachnoid hemorrhage," Neurological Research, vol. 28, no. 4, pp. 399-414, 2006.

[48] G. Xi, R. F. Keep, and J. T. Hoff, "Mechanisms of brain injury after intracerebral haemorrhage," Lancet Neurology, vol. 5, no. 1, pp. 53-63, 2006.

[49] D. O. Bates, N. J. Hillman, B. Williams, C. R. Neal, and T. M. Pocock, "Regulation of microvascular permeability by vascular endothelial growth factors," Journal of Anatomy, vol. 200, no. 6, pp. 581-597, 2002.

[50] A. T. Argaw, B. T. Gurfein, Y. Zhang, A. Zameer, and G. R. John, "VEGF-mediated disruption of endothelial CLN-5 promotes blood-brain barrier breakdown," Proceedings of the National Academy of Sciences of the United States of America, vol. 106, no. 6, pp. 1977-1982, 2009.

[51] M. J. McGirt, G. Pradilla, F. G. Legnani et al., "Systemic administration of simvastatin after the onset of experimental subarachnoid hemorrhage attenuates cerebral vasospasm," Neurosurgery, vol. 58, no. 5, pp. 945-951, 2006.

[52] M. Sykora, J. Diedler, A. Rupp, P. Turcani, A. Rocco, and T. Steiner, "Impaired baroreflex sensitivity predicts outcome of acute intracerebral hemorrhage," Critical Care Medicine, vol. 36, no. 11, pp. 3074-3079, 2008.

[53] L. Manning, Y. Hirakawa, H. Arima et al., "Blood pressure variability and outcome after acute intracerebral haemorrhage: a post-hoc analysis of INTERACT2, a randomised controlled trial," The Lancet Neurology, vol. 13, no. 4, pp. 364-373, 2014.

[54] J. M. Wardlaw, C. Smith, and M. Dichgans, "Mechanisms of sporadic cerebral small vessel disease: insights from neuroimaging," The Lancet Neurology, vol. 12, no. 5, pp. 483-497, 2013.

[55] R. F. Keep, Y. Hua, and G. Xi, "Intracerebral haemorrhage: mechanisms of injury and therapeutic targets," The Lancet Neurology, vol. 11, no. 8, pp. 720-731, 2012. 


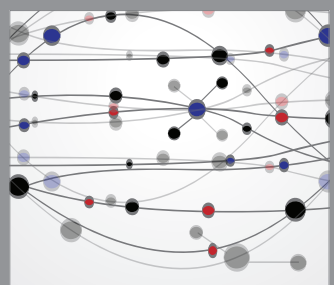

The Scientific World Journal
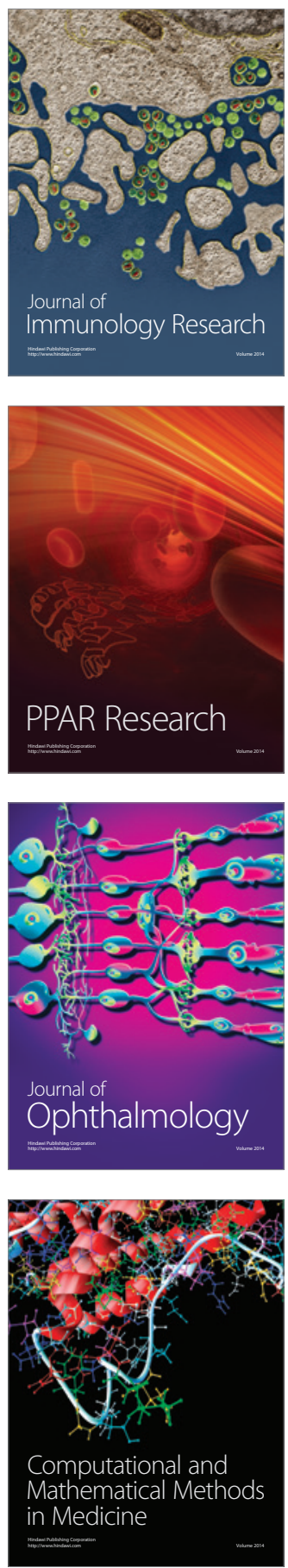

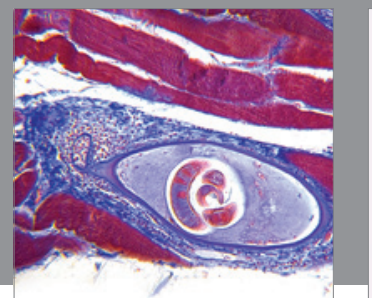

Gastroenterology

Research and Practice
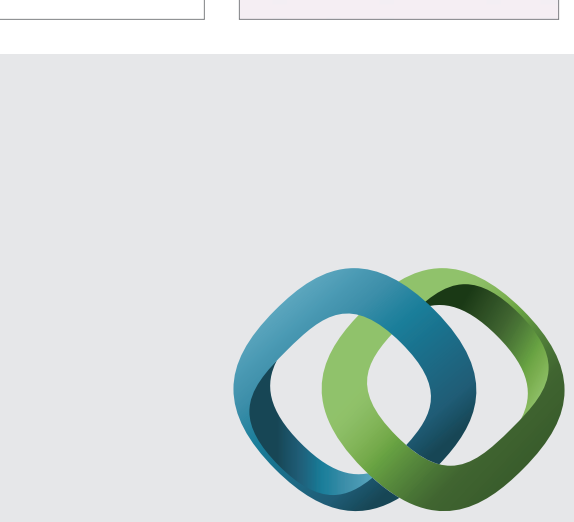

\section{Hindawi}

Submit your manuscripts at

http://www.hindawi.com
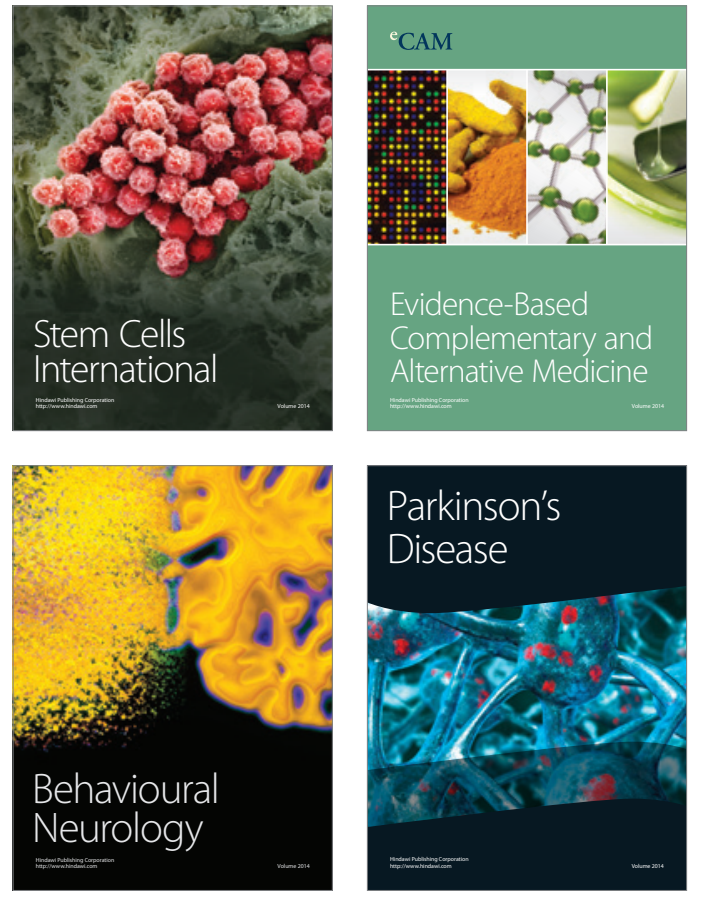
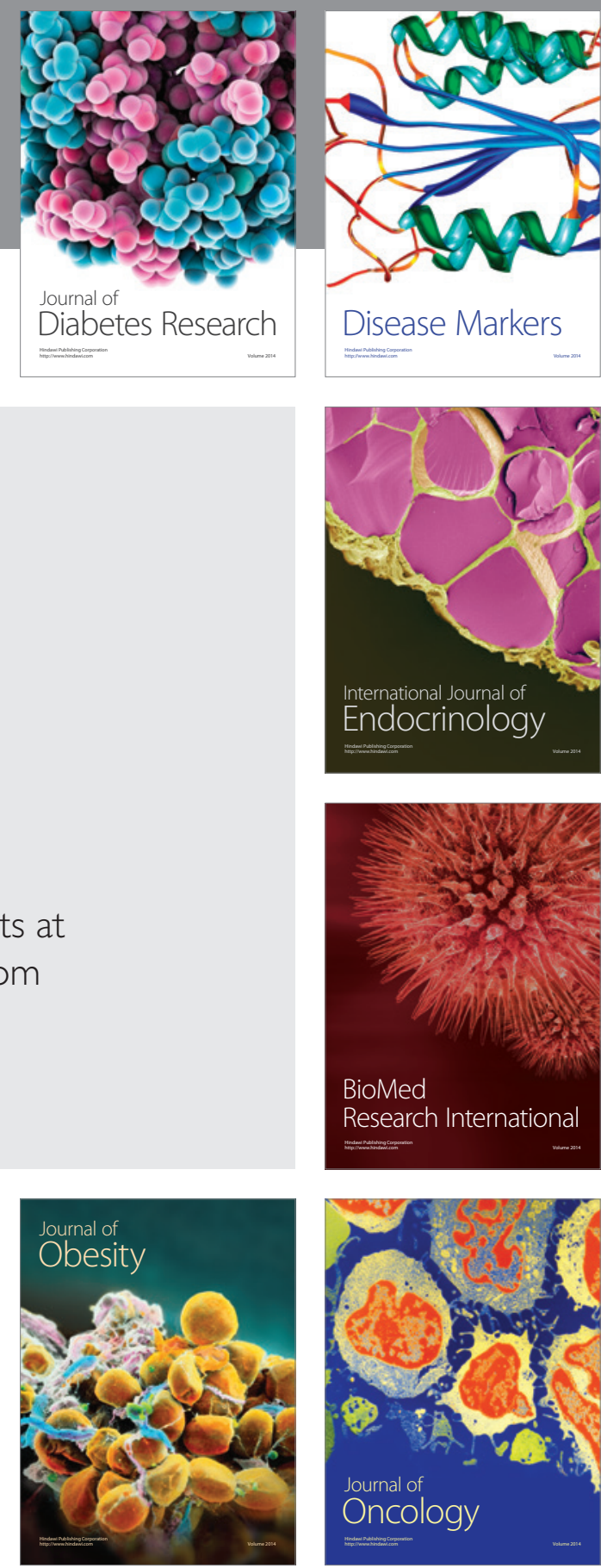

Disease Markers
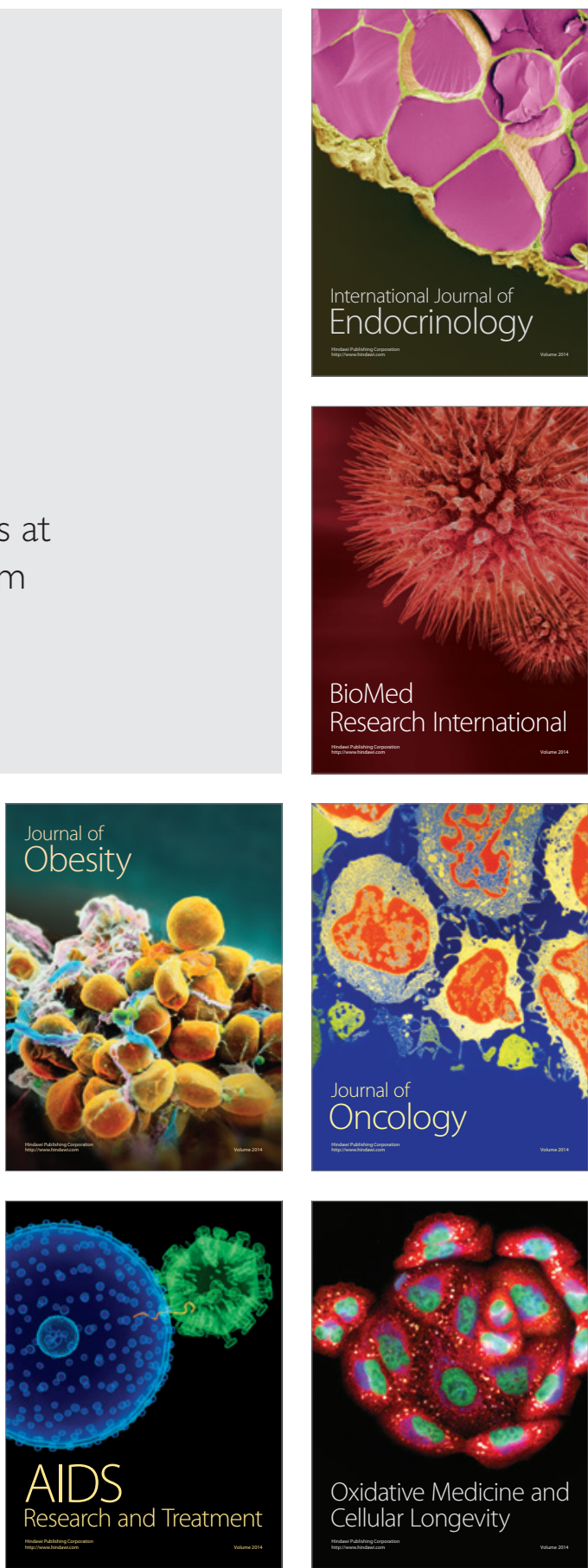